\title{
Erratum to: Evaluation of Skin Permeation of $\beta$-Blockers for Topical Drug Delivery
}

\author{
Doungdaw Chantasart • Jinsong Hao $\cdot$ S. Kevin Li
}

Published online: 23 December 2014

(C) Springer Science+Business Media New York 2014

\section{Erratum to: Pharm Res}

DOI 10.1007/s11095-012-0928-9

The references cited in the text and Table 1 for the pKa and $\log \mathrm{KO} / \mathrm{W}$ values of betaxolol, timolol, and atenolol are incorrect. Although this does not affect the conclusion in the paper, it will affect the readers who want to use the references in their studies and investigations. The errors are described below:

Pages 867-868: The references for the pKa and log KO/ $\mathrm{W}$ values of betaxolol, timolol, and atenolol cited in the text and Table 1 are incorrect. The correct references are:

Betaxolol: $\log \mathrm{KO} / \mathrm{W}$ :

Product Monograph, Betoptic S, Alcon Canada, Control \#049005, http://www.visioninstitute.optometry.net/ UserFiles/users/499/File/BETOPTIC\%20S\%20-\% 20ALCON.pdf

Timolol: pKa and log KO/W:

Reference \#33, Denet et al. Pharm Res. 2003;20:1946-51.

Atenolol: $\log \mathrm{KO} / \mathrm{W}$ :

Reference \#20, Burgot et al. Int J Pharm. 1990;63:73-6.

We hope this error does not cause any inconvenience to the readers.

The online version of the original article can be found at http://dx.doi.org//0. | 007/s | | 095-0 |2-0928-9.

D. Chantasart · J. Hao · S. K. Li ( $\varangle)$

Division of Pharmaceutical Sciences, College of Pharmacy, University of Cincinnati, 3225 Eden Avenue, 136 HPB, Cincinnati, OH 45267, USA

e-mail: likv@uc.edu

Present Address:

D. Chantasart

Department of Pharmacy, Faculty of Pharmacy, Mahidol University

Bangkok 10400, Thailand 